\title{
Inteligência territorial para o desenvolvimento agropecuário de Roraima
}

\section{Gustavo Spadotti Amaral Castro}

Analista da Empresa Brasileira de Pesquisa Agropecuária (Embrapa), Doutor em Agricultura pela Faculdade de Ciências Agronômicas da Universidade Estadual Paulista "Júlio de Mesquita Filho" (Unesp), http:// lattes.cnpq.br/6332419122318999, gustavo.castro@embrapa.br.

\section{Lucíola Alves Magalhães}

Analista da Empresa Brasileira de Pesquisa Agropecuária (Embrapa), Doutora em Ciências pela Universidade Estadual de Campinas (Unicamp), http://lattes.cnpq.br/7190198966107091, luciola.magalhaes@embrapa.br.

\section{Marcelo Fernando Fonseca}

Analista da Empresa Brasileira de Pesquisa Agropecuária (Embrapa), Doutor em Ciências pela Universidade Estadual de Campinas (Unicamp), http://lattes.cnpq.br/ 1794882371177104, marcelo.fonseca@embrapa.br.

\section{Alfredo Kingo Oyama Homma}

Pesquisador da Empresa Brasileira de Pesquisa Agropecuária (Embrapa), Doutor em Economia Rural pela Universidade Federal de Viçosa (UFV), http://lattes.cnpq.br/1026511676619526, alfredo.homma@ embrapa.br.

\section{Evaristo Eduardo de Miranda}

Pesquisador da Empresa Brasileira de Pesquisa Agropecuária (Embrapa), Doutor em Ecologia pela Université de Montpellier II, França, http://lattes.cnpq.br/0569813112754116, evaristo.miranda@embrapa.br.

Submetido em: 22/08/2017. Aprovado em: 24/10/2017. Publicado em: 22/02/2018.

\section{RESUMO}

O estado de Roraima tem boa parte do seu território no Hemisfério Norte e é o mais setentrional dos estados brasileiros. A agropecuária participa com apenas 4,3\% no PIB do estado, que apresenta alta concentração populacional na capital e enorme intervenção do governo federal, que atribuiu para Unidades de Conservação e Terras Indígenas $67 \%$ de seu território. O estado enfrenta dificuldades em seu desenvolvimento agrícola e socioeconômico. Conhecer seu território e suas particularidades é essencial para subsidiar a elaboração de projetos e ações público/privadas voltadas para o desenvolvimento da agropecuária e dos agricultores do estado. O objetivo deste trabalho é aprofundar a discussão sobre o contexto territorial do uso, ocupação e atribuição das terras do estado de Roraima. O método aplicado para subsidiar essa discussão utiliza como base o Sistema de Inteligência Territorial Estratégica (SITE), que permite uma visão integrada e multifatorial do território. Com isso foi possível avaliar os quadros natural, agrário, agrícola, socioeconômico e de infraestrutura do estado, bem como suas interações. Até o momento, as análises do SITE Roraima permitiram a identificação de propostas, programas e atuações pontuais e estratégicas para aumento da competitividade agropecuária do estado.

Palavras-chave: Sustentabilidade. Políticas públicas. Transferência de tecnologia. 


\section{Use of territorial intelligence for agricultural development in Roraima}

\section{ABSTRACT}

The state of Roraima has a large portion of its territory in the Northern Hemisphere and is the most northern of the Brazilian states. The agricultural sector accounts for only $4.3 \%$ of the state's GDP, which has a high concentration of population in the capital and enormous intervention by the federal government, which has allocated $67 \%$ of its territory to Conservation Units and Indigenous Lands. The state faces difficulties in its agricultural and socioeconomic development. Knowing its territory and its peculiarities is essential to subsidize the elaboration of public and private projects and actions aimed at the development of agriculture and state farmers. The objective of this work is to deepen the discussion about the territorial context of the use, occupation and attribution of the lands of the state of Roraima. The method used to support this discussion uses the Strategic Territorial Intelligence System (SITE) as a basis, which allows an integrated and multifactorial view of the territory. With this, it was possible to evaluate the natural, agrarian, agricultural, socioeconomic and infrastructure of the state, as well as their interactions. So far, the analysis of SITE Roraima allowed the identification of proposals, programs and specific and strategic actions to increase the agricultural competitiveness of the state.

Keywords: Sustainability. Public policy. Technology transfer.

\section{Inteligencia territorial para el desarrollo de la actividad agropecuaria de Roraima}

\section{RESUMEN}

El estado de Roraima tiene buena parte de su territorio en el Hemisferio Norte y es el más septentrional de los estados brasileños. La agropecuaria participa con apenas 4,3\% en el PIB del estado, que presenta alta concentración poblacional en la capital y enorme intervención del gobierno federal, que atribuyó a Unidades de Conservación y Tierras Indígenas el $67 \%$ de su territorio. El estado enfrenta dificultades en su desarrollo agrícola y socioeconómico. Conocer su territorio y sus particularidades es esencial para subsidiar la elaboración de proyectos y acciones público / privadas dirigidas al desarrollo de la agropecuaria y de los agricultores del estado. El objetivo de este trabajo es profundizar la discusión sobre el contexto territorial del uso, ocupación y atribución de las tierras del estado de Roraima. El método aplicado para subsidiar esta discusión utiliza como base el Sistema de Inteligencia Territorial Estratégica (SITE), que permite una visión integrada y multifactorial del territorio. Con eso fue posible evaluar los cuadros natural, agrario, agrícola, socioeconómico y de infraestructura del estado, así como sus interacciones. Hasta el momento, los análisis del SITE Roraima permitieron la identificación de propuestas, programas y actuaciones puntuales y estratégicas para aumentar la competitividad agropecuaria del estado.

Palabras clave: Sostenibilidad. Políticas públicas. Transferencia de tecnología. 


\section{INTRODUÇÃO}

Fundado como território de Rio Branco (posteriormente Roraima) em 1943 no governo Getúlio Vargas (1882-1954), e elevado à categoria de estado em 1988 com a promulgaçáo da Constituiçáo Nacional, o estado de Roraima é uma das 27 unidades federativas do Brasil. Tendo sua capital Boa Vista situada no Hemisfério Norte, é o mais setentrional dos estados. Possui limites internacionais com a Venezuela ao norte e noroeste e com a Guiana ao leste e, nacionalmente, faz divisa com o Pará ao sudeste e Amazonas ao sul e oeste, com área territorial de $224.301 \mathrm{~km}^{2}$ (IBGE, 2016).

Com população estimada em 505.665 habitantes ${ }^{1}$, é o menos populoso dentre os estados brasileiros, registrando também a menor densidade demográfica, com 2,25 hab. $/ \mathrm{km}^{2}$. Sua economia tem forte dependência de empregos do setor público $(84,5 \%)$, seguido do setor industrial com $11,2 \%$, e embora seu produto interno bruto (PIB) seja o menor do país $(0,2 \%)$, com $\mathrm{R} \$ 9,744$ bilhôes, registra crescimento acima de 4,1\% desde 2010 (IBGE, 2016). O grau de importância do agronegócio é considerado baixo. Em 2014, por exemplo, o valor adicionado bruto da agropecuária representou cerca de 4,3\% do PIB do estado.

Soma-se a complexidade histórica deste estado a batalha pela conquista da soberania territorial, culminada no recente Decreto no 8.586, de 9 de novembro de 2015 , que regulamenta a Lei ${ }^{\circ}$ 10.304 de 5 de novembro de 2001, que dispôs sobre a transferência das terras antigamente pertencentes à Uniấo ao domínio do estado de Roraima (BRASIL, 2015).

Dado seu histórico isolamento territorial causado pela distância dos principais polos nacionais e das dificuldades logísticas implícitas à Região Norte, que resultam em custos superiores para aquisição de alimentos e insumos agropecuários, fazemse necessários estudos detalhados que busquem o abastecimento interno focado na expansão

\footnotetext{
${ }^{1}$ População estimada em 2015. O Censo Demográfico 2010 mostrava que $76,55 \%$ da população de Roraima já viviam em áreas urbanas.
}

da produção agrícola, garantindo a segurança alimentar e o desenvolvimento sustentável do estado de Roraima, baseados no respeito ao ambiente e às populaçóes e comunidades tradicionais.

As dificuldades para a elaboração de estudos em base territorial sobre o estado de Roraima trespassam múltiplos aspectos que vão das dificuldades técnicas no processo de obtençáo de dados, em geral dispersos em diversos órgãos oficiais, culminando na incompatibilidade entre os dados, que limita ou impede a elaboração de consultas. Com isso, a construçáo de cenários que requerem o cruzamento de informaçóes se torna complexa.

Com base no exposto, este trabalho buscou promover uma discussão sobre o contexto territorial de Roraima com foco no desenvolvimento agropecuário. Objetivou-se reunir, padronizar e explorar dados dispersos em diversas bases e órgáos competentes, apresentando-os em bases territoriais. O intuito foi elencar demandas relevantes para elaboração de cenários e identificação de territórios que contribuam para fortalecer os agricultores, o agronegócio no estado e ampliar sua importância econômica por meio de açôes de políticas públicas.

\section{METODOLOGIA}

A inteligência territorial emprega conceitos e métodos que permitem superar vários limites das políticas públicas de inovação para o desenvolvimento agropecuário, historicamente, baseadas em cadeias produtivas e/ou em categorias de agricultores. Essa inovaçáo metodológica foi aplicada com sucesso na caracterização geoeconômica do MATOPIBA (MIRANDA et al., 2014) e na construção de agendas para a inovação e o desenvolvimento sustentável da agropecuária em diversas regióes do país e no tratamento de questóes de forte componente territorial como a macrologística da agropecuária nacional.

Ela implica a estruturação de Sistemas de Inteligência Territorial Estratégica (SITE), baseados em geotecnologias, capazes de integrar e analisar informaçôes dos quadros natural, agrário, 
agrícola, infraestrutura e socioeconômico do espaço rural, em diversas escalas temporais e espaciais (MIRANDA et al., 2014b), como os desenvolvidos nos últimos anos pelo Grupo de Inteligência Territorial Estratégica (GITE) da Embrapa para diversas regióes do Brasil.O quadro agrário mostra as áreas que estão legalmente atribuídas, caracterizadas como oficialmente constituídas por deliberações, decretos e atos de diversos órgãos e instâncias administrativas da federação. $\mathrm{O}$ quadro natural mostra os aspectos físicos da região estudada, como hidrografia, relevo, solos, potencial mineral etc. $\mathrm{O}$ quadro agrícola apresenta os elementos da produção agropecuária. O quadro de infraestrutura apresenta modais de transporte e estruturas logísticas disponíveis na área estudada. $\mathrm{O}$ quadro socioeconômico mostra os indicadores de desenvolvimento econômico e humano (PIB, IDH, renda rural etc.).

Essa visão abrangente e multifatorial favorece a análise integrada das situaçóes territoriais e a geração de cenários evolutivos fornecendo subsídios para a elaboração de sínteses de contextualização e qualificação territorial para a melhor compreensão e gestáo do território, fundamentais para tomada de decisōes estratégicas (MIRANDA et al., 2014). Esse sistema é dinâmico e conta atualmente com uma centena de planos de informaçôes distribuídos nas cinco dimensôes, acima mencionadas.

Para a estruturação do SITE Roraima, foi organizada uma base de dados padronizada compreendendo dados obtidos a partir das informações de órgãos oficiais públicos: Instituto Brasileiro de Geografia e Estatística (IBGE, 2016); Companhia Nacional de Abastecimento (Conab, 2015); Departamento Nacional de Infraestrutura de Transportes (Dnit, 2016); Departamento Nacional de Produção Mineral (DNPM, 2015); Fundação Nacional do Índio (Funai, 2014); Instituto Chico Mendes de Conservação da Biodiversidade (ICMBio, 2014); Ministério do Meio Ambiente (MMA, 2014); Instituto Nacional de Colonização e Reforma Agrária (Incra, 2014) e Secretaria de Políticas de
Promoção da Igualdade Racial (Seppir, 2014). Esses dados tratam, por exemplo, de temas referentes às divisōes administrativas oficiais, aspectos do meio físico, dados de produção agropecuária, da estrutura fundiária, atribuição das terras, atualizações censitárias, logística, infraestrutura e indicadores socioeconômicos. Também foram consultados atores locais, tanto do governo estadual como de associações de produtores rurais, bem como realizadas apresentaçóes locais para validaçáo dos dados elaborados. A partir de cruzamentos entre os planos de informação foram gerados novos dados com uso do sistema de informação geográfico (SIG), especificamente do software ArcGIS 10.3 (ESRI, 2013).

\section{RESULTADOS E DISCUSÃO}

\section{QUADRO AGRÁRIO}

O estado apresenta complexo quadro agrário em virtude da pluralidade de situaçóes e das já conhecidas problemáticas fundiárias características do território nacional, destacadamente da Região Norte. Nesta regiáo os processos de ocupação e, principalmente legalização das terras, sob o ponto de vista da jurisprudência estadual com relação à titulação definitiva das propriedades rurais, tornaram conflitivas as relações entre áreas legalmente atribuídas e propriedades rurais privadas (IGNÁCIO et al., 2016). Nesse escopo está o conjunto de Unidades de Conservaçáo (UCs), Terras Indígenas (TIs) e projetos de reforma agrária por meio de Assentamentos Rurais (ARs). Importante lembrar que, mesmo sem titulação definitiva, historicamente muitas áreas devolutas foram ocupadas por produtores rurais, pecuaristas, extrativistas e ribeirinhos, que solicitam o direito de titulação após a publicação do Decreto no 8.586 , que consolidou o repasse das terras da União para o Estado. 
Uma síntese do quadro agrário de Roraima foi realizada a partir dos dados levantados junto à Funai, ICMBio, MMA, Secretarias Estaduais e Municipais do Meio Ambiente e Incra. Não foram consideradas nos cálculos as áreas incluídas nas Zonas de Amortecimento das Unidades de Conservação, em virtude deste dado depender, concretamente, dos planos de manejo específicos de cada unidade e pelo fato de haver também lacunas nos dados e algumas controvérsias quanto a essa delimitação.

No entanto, foram detectadas sobreposições territoriais no conjunto de informaçóes avaliadas. No caso das UCs de uso sustentável, por exemplo, ocorre a presença de assentamentos da reforma agrária e sobreposiçôes com terras indígenas. Assim, calculadas e descontadas as sobreposiçóes de áreas, com a aplicaçáo de técnicas de geoprocessamento, o conjunto das áreas legalmente atribuídas (UCs, TIs e ARs) alcança 16.316 .700 ha, ou $73 \%$ da área total do estado de Roraima. Segundo a Seppir (2014), não existem comunidades quilombolas no estado. A figura 1 apresenta a distribuição espacial desses territórios no estado.

O estado possui, portanto, cerca de 6,1 milhóes de hectares não atribuídos. Desses, há de se respeitar as exigências do Novo Código Florestal, que exigem a preservação das áreas de reserva legal e das áreas de preservaçáo permanente em percentuais distintos aplicados para cada bioma (BRASIL, 2012). No bioma amazônico, no qual Roraima está inserido, a legislaçấo exige reserva legal de $80 \%$ em ambientes florestais, 35\% em áreas de cerrado e 20\% em áreas de campos nativos.
Roraima possui área de $224.301 \mathrm{~km}^{2}$, dividida em 15 municípios. Como mostra a tabela 1 , de um total de 98 áreas legalmente atribuídas em Roraima, 13 Unidades de Conservação ocupam extensão total aproximada de 4,7 milhóes de hectares. Existem 33 terras indígenas demarcadas, com aproximadamente 10,4 milhôes de hectares, além de 52 assentamentos de reforma agrária com aproximadamente 1,4 milhão de hectares, totalizando quase 16,5 milhóes de hectares legalmente atribuídos (FUNAI, 2014; ICMBio 2014; MMA 2014; INCRA, 2014) ou cerca de $74 \%$ da área de Roraima.

Tema recorrente entre os assentados da reforma agrária é a titulação das suas terras pelo Incra. Nos 52 ARs vivem 15.919 famílias, cerca de 60 mil pessoas. Uma análise da data de criação destes assentamentos (tabela 2) indica que 29\% dos ARs possuem menos de 10 anos de criaçáo, enquanto outros $71 \%$ possuem mais de 10 anos. Este poderia ser um critério a ser adotado para priorizar a titulaçáo das mais de 14 mil famílias que vivem nesta situação (FONSECA et al., 2016). Isso porque existe alto grau de dependência entre titulaçáo definitiva destas áreas e a aquisição de financiamentos agrícolas fornecidos pelas instituições bancárias, especialmente aqueles ligados a investimento. De posse da escritura, o produtor possui garantias suficientes para solicitar crédito agrícola aos bancos a fim de promover maior inclusão produtiva, social e econômica, um dos objetivos da reforma agrária no país.

Tabela 1 - Classificação e quantificação das áreas atribuídas em Roraima em 2014

\begin{tabular}{llll} 
& Quantidade & Área $\left(\mathrm{km}^{2}\right)$ & $\%$ da área do Estado \\
\hline Unidades de Conservação & 13 & 46.987 & $21 \%$ \\
\hline Terras Indígenas & 33 & 103.833 & $46 \%$ \\
\hline Assentamentos Rurais & 52 & 13.933 & $6 \%$ \\
\hline $\begin{array}{l}\text { Áreas Legalmente Atribuídas } \\
\text { ('descontadas as sobreposições) }\end{array}$ & 98 & $163.167^{*}$ & $73 \%$ \\
\hline
\end{tabular}

Fonte: MMA; ICMBio; Funai; Incra, 2014 
Figura 1 - Áreas legalmente atribuídas no estado de Roraima em 2014

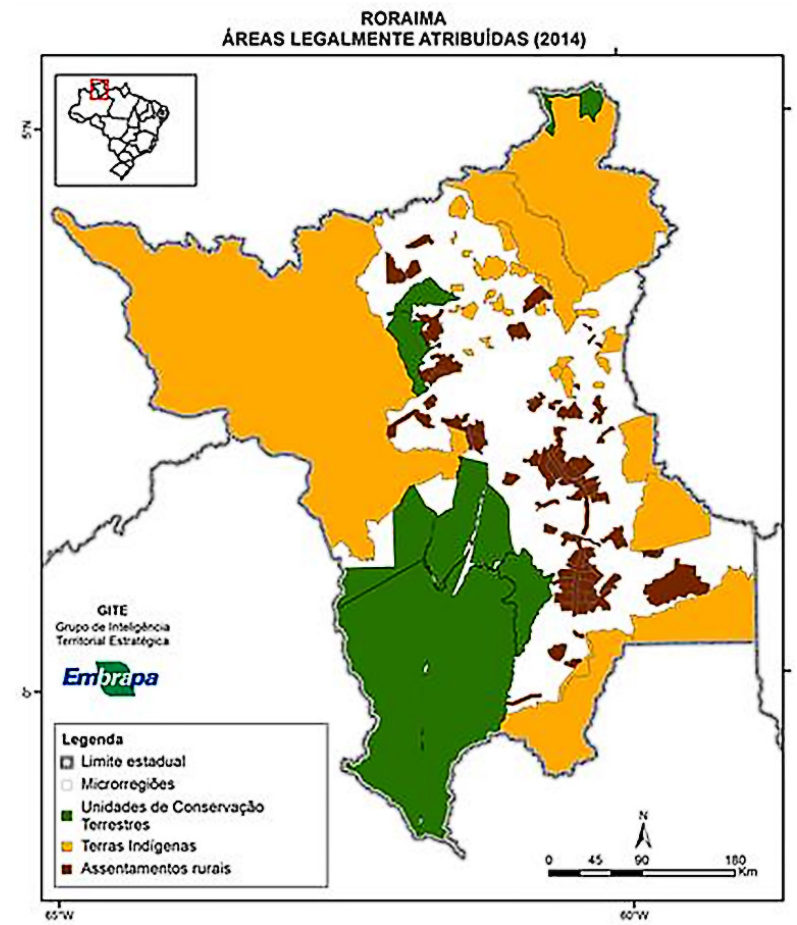

Fonte: MMA; ICMBio; Funai; Incra, 2014

Tabela 2 - Classificação e quantificação dos assentamentos rurais de acordo com o período de criação

\begin{tabular}{ll}
$\begin{array}{l}\text { Assentamentos da Reforma Agrária } \\
\text { Período de Criação }\end{array}$ \\
\hline Menos de 10 Anos & Mais de 10 Anos \\
\hline 15 assentamentos $(29 \%)$ & 37 assentamentos $(71 \%)$ \\
\hline 1.514 famílias $(10 \%)$ & 14.405 famílias $(90 \%)$ \\
\hline 157.933 hectares $(11 \%)$ & 1.235 .425 hectares $(89 \%)$
\end{tabular}

Fonte: Incra, 2014.

\section{QUADRO NATURAL}

Roraima apresenta três tipos de coberturas vegetais bem definidas, além de suas subclasses (MMA, 2016). As áreas de florestas predominam no território, como mostra a figura 2. São aproximadamente 15 milhóes de hectares, cerca de $67 \%$ do estado. Na regiáo nordeste e na sudoeste, ocorre o domínio das savanas (localmente denominado Lavrado) e das campinaranas, com 3,4 e 3 milhôes de hectares, respectivamente. Notam-se poucas áreas antropizadas, predominantemente próximas aos municípios e rodovias que as interligam.
$\mathrm{Na}$ região do Lavrado estão inseridos nove municípios que são responsáveis pela maior parte da produçáo agrícola do estado. Este ambiente, composto por gramíneas e espécies menos robustas, consequentemente de maior facilidade de manejo, tem sido preferido pelos médios e grandes agricultores devido à facilidade de mecanização. Por outro lado, pequenos agricultores preferem áreas de mata ou de contato cerrado/floresta, devido à maior fertilidade natural destes solos (CARVALHO; CARVALHO; MORAIS, 2016). Cinco municípios possuem mais de $70 \%$ de suas áreas inseridas no Lavrado, que totalizam mais de 4,2 milhões de hectares.

Figura 2 - Mapa de vegetação e da área do lavrado

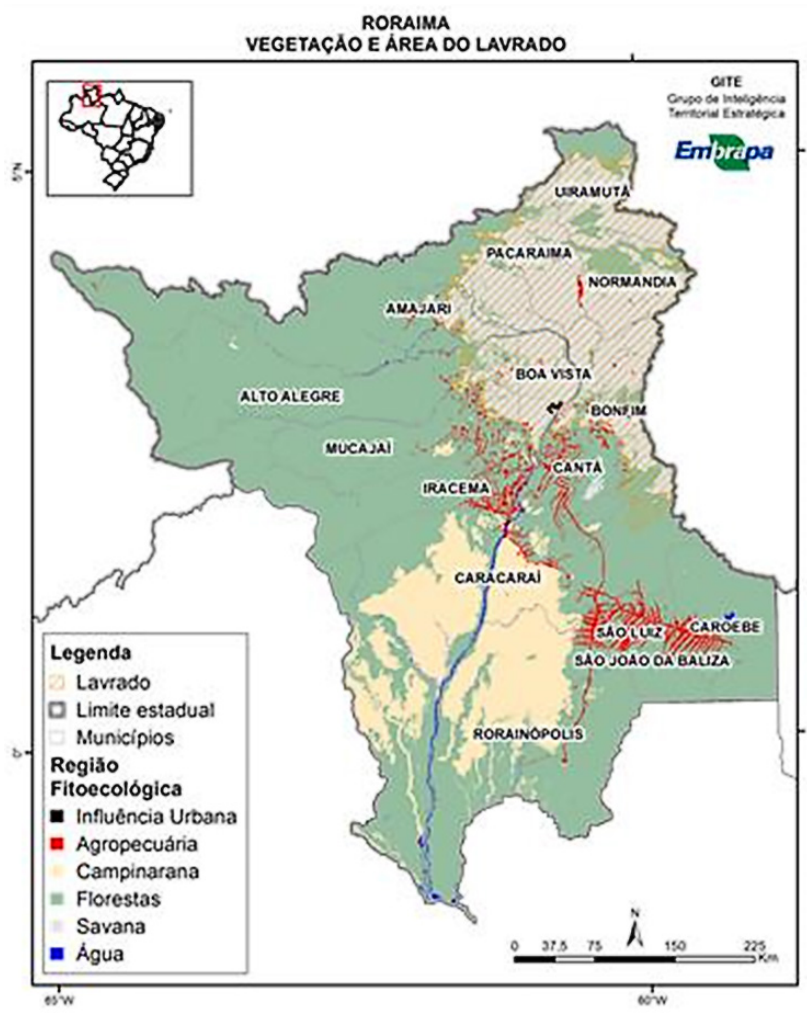

Fonte: MMA, 2014

Se somássemos aos 6,1 milhôes de hectares livres (i.e, fora das áreas legalmente atribuídas) os 1,4 milhóes de hectares dos ARs, Roraima ainda teria aproximadamente 7,5 milhóes de hectares passíveis de utilização, sem considerar os outros usos (massa d'água, áreas urbanas etc.). Destes, aproximadamente $534 \mathrm{mil} \mathrm{hectares} \mathrm{(-7 \% )} \mathrm{já} \mathrm{são}$ utilizados para fins agropecuários (MMA, 2006). 
Tabela 3 - Municípios em áreas do lavrado

\begin{tabular}{llrrr}
\hline ID & Município & Área Município $\left(\mathrm{km}^{2}\right)$ & Área Lavrado $\left(\mathrm{km}^{2}\right)$ & \% do Município \\
\hline 1 & Boa Vista & 5.687 & 5.658 & 99,5 \\
\hline 2 & Normandia & 6.966 & 6.767 & 97,1 \\
\hline 3 & Bonfim & 8.095 & 7.458 & 92,1 \\
\hline 4 & Pacaraima & 8.028 & 6.929 & 86,3 \\
\hline 5 & Uiramutã & 8.065 & 6.029 & 74,7 \\
\hline 6 & Amajari & 28.472 & 5.452 & 19,1 \\
\hline 7 & Alto Alegre & 25.567 & 3.195 & 12,5 \\
\hline 8 & Cantá & 7.664 & 816 & 10,6 \\
\hline 9 & Caracaraí & 47.411 & 548 & 1,1 \\
\hline
\end{tabular}

Fonte: MMA, 2014

Prevendo possíveis expansôes da agropecuária no estado, focadas no ambiente cerrado, ou seja, na área do lavrado, que totaliza 1,47 milhão de hectares disponíveis (já descontadas UCs e TIs), deve-se ainda descontar a área de reserva legal (35\%), percentual obrigatório de acordo com o código florestal. Portanto, 515 mil hectares do lavrado já seriam preservados por lei dentro das propriedades agrícolas, restando para a expansão agropecuária 956 mil hectares. Contudo, devese salientar que nem toda esta área é passível de utilização, haja vista que ela contempla áreas de pouco interesse ou de severas limitaçóes. Portanto, para se obter uma previsão de área passível de expansão, seria necessária uma análise da aptidão agrícola destas terras (MARTINHO et al., 2016) e/ou do potencial de utilizaçáo com base nos critérios de um Zoneamento Ecológico Econômico (IGNÁCIO et al., 2016).

Quanto à exploração de insumos agrícolas, o estado não detém reservas oficialmente comprovadas de minerais para uso na agricultura. Os títulos minerários para calcário, fosfato e sais de potássio (figura 3) estão em fase de requerimento ou autorização de pesquisa (DNPM, 2015). É um dos poucos estados que não possui exploração própria de calcário em escala comercial (PARAHYBA, 2009) e importa este insumo do Pará, do município de Itaituba, conduzida por barcaças, em trajeto longo e difícil.
É estratégico para o estado facilitar a disponibilidade de insumos para o desenvolvimento de hortifrutigranjeiros para o abastecimento de Boa Vista, que concentra $62,22 \%$ da população estadual (2010).

Figura 3 - Títulos minerários das substâncias cadastradas para uso na agricultura

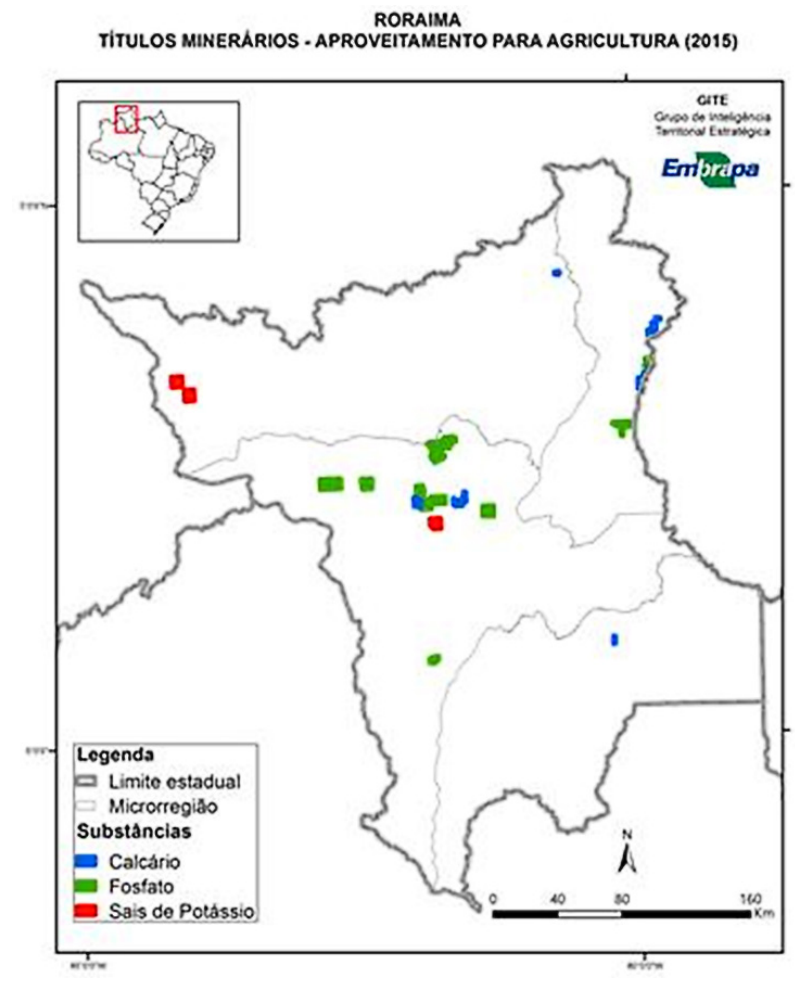

Fonte: DNPM, 2015 


\section{QUADRO AGRÍCOLA}

Os dados utilizados para ilustrar o quadro agrícola de Roraima provêm do IBGE. Eles correspondem a dois tipos de levantamentos: dados do censo agropecuário do ano de 2006 e dados dos levantamentos anuais (Produção Agrícola Municipal, 2015). Também foram analisadas as últimas previsóes de safra disponibilizadas pela Conab (2015). Com exceção dos dados de previsão, que são divulgados considerando a totalidade do estado, os demais podem ser trabalhados até o nível municipal, o que permite formar uma avaliação detalhada do desempenho da agricultura na região.

Para obter a importância relativa dos diferentes produtos, foi feito um exercício considerando o valor de cada um, como média trienal de 2006 a 2008, em uma tentativa de aproximação ao último levantamento censitário (GARAGORRY et al., s/d). Para obter a média trienal foi usado o índice IGP-DI da FGV. Seguindo a metodologia usada em outros estudos sobre concentração (GARAGORRY; CHAIB FILHO, 2008; GARAGORRY; PENTEADO FILHO, 2012; WANDER et al., 2013), após o ordenamento dos valores, foram determinados os quartéis de valor da produção (GARAGORRY et al., 2016).
O grupo 75 (abreviado G75) reúne os produtos necessários e suficientes para gerar $75 \%$ do valor total da produção do estado. Em Roraima, apenas seis produtos fazem parte desse grupo, como mostra a tabela 4 . Sozinho, o arroz representa $28 \%$ do valor total da produção.

Acrescentando a produção de bovinos e mandioca, obtém-se $57 \%$ do valor total de produçáo do estado. Adicionando a madeira, a banana e a soja, atingese $79 \%$ do total. A expansáo de arroz irrigado no estado de Roraima permitiu o abastecimento desse produto para a cidade de Manaus e de outros núcleos urbanos até a sua desativação das terras ocupadas situadas à margem direita da rodovia BR 174 (inaugurada em 1977 e asfaltada somente em 1998), sentido fronteira da Venezuela. Em junho de 2007, o Supremo Tribunal Federal (STF) determinou a desocupação da Terra Indígena Raposa Serra do Sol, onde os arrozeiros haviam-se instalado no início da década de 1970. Em 20 de março de 2009, a decisão final do STF confirmou a homologação contínua da Terra Indígena Raposa Serra do Sol, determinando a retirada dos náo indígenas da região (HOMMA, 2015).

Tabela 4 - Valor da produção agropecuária de Roraima (média trienal 2006 a 2008)

\begin{tabular}{lrrrr} 
Produto & Valor $(\mathrm{R} \$ 1.000)$ & $\sum$ Valor $(\mathrm{R} \$ 1.000)$ & $\%$ & $\%$ acum. Total \\
\hline Arroz & 62.855 & 62.855 & 28,05 & 28,05 \\
\hline Bovinos & 37.096 & 99.951 & 16,56 & 44,61 \\
\hline Mandioca & 27.682 & 127.633 & 12,36 & 56,97 \\
\hline Madeira em tora & 21.650 & 149.282 & 9,66 & 66,63 \\
\hline Banana & 15.846 & 165.128 & 7,07 & 73,70 \\
\hline Soja & 11.943 & 177.072 & 5,33 & 79,03 \\
\hline
\end{tabular}

Fonte: Garagorry, 2016. 
Dados atuais sobre a quantidade produzida das categorias correspondentes a esses principais produtos foram analisados. Com esse enfoque, foram consideradas classificaçôes mais abrangentes de produção: segurança alimentar, grãos, frutas, hortaliças, madeira e pecuária.

A segurança alimentar possui papel fundamental no atendimento às necessidades básicas da população local. Soma-se a isso o fato de $63,4 \%$ da população do estado residir na capital Boa Vista (IBGE, 2014). $\mathrm{O}$ arroz, que agregava maior valor na produçáo agropecuária do estado, sofreu redução expressiva das áreas a partir de 2012, como mostra a tabela 5. Devido ao embargo da área produtora de arroz, alguns agricultores se deslocaram para a ilha de Marajó, no Pará, onde passaram a desenvolver este cultivo a partir de 2010. A produção de feijão, no entanto, tem se mantido aparentemente estável. Investimentos em tecnologia para pequenos e médios produtores (mecanização), redução do custo dos insumos, incentivos a vocação natural da produção de arroz (irrigado e sequeiro) e a inclusão do feijão em esquemas de rotação de culturas poderiam fortalecer a segurança alimentar no estado.

Tabela 5 - Área, produçấo e produtividade das culturas do arroz e feijão

\begin{tabular}{lllllll}
\cline { 2 - 7 } & 2012 & 2015 & $2016^{*}$ & 2012 & 2015 & $2016^{*}$ \\
\cline { 2 - 7 } & \multicolumn{3}{c}{ Arroz } & \multicolumn{3}{c}{ Feijão } \\
\hline Área (ha) & 19.775 & 7.964 & 8.628 & 2.987 & 2.688 & 2.688 \\
\hline Produção (t) & 106.681 & 53.003 & 54.755 & 1.992 & 1.964 & 1.955 \\
\hline $\begin{array}{l}\text { Produtividade } \\
\text { (tha) }\end{array}$ & 5,4 & 6,7 & 6,3 & 0,67 & 0,73 & 0,73 \\
\hline
\end{tabular}

Fonte: IBGE, 2016

No que tange às demais culturas graníferas, existe grande potencial produtivo para soja, milho, sorgo, girassol e feijão-caupi. A posição estratégica do estado, com ligaçóes a mercados demandantes, sejam nacionais ou internacionais, e a possibilidade de produção na entressafra brasileira são diferenciais. Contudo, produzir em áreas de cerrado demanda o uso de tecnologias de ponta para obtençáo de altas produtividades com sustentabilidade ambiental, devido à baixa fertilidade natural dos solos destas áreas (CASTRO et al., 2016). Fazem-se necessários esforços nas áreas de correçáo do solo, incentivo ao plantio direto, rotação de culturas, integração lavourapecuária-floresta (ILPF) e demais práticas sugeridas pelo Programa de Agricultura de Baixo Carbono (Programa ABC). Por ser uma regiáo isolada, pode fornecer produtos diferenciados, como sojas não transgênicas para mercados específicos de maior valor agregado. Para tal, foi fundamental o recente zoneamento de risco climático do estado, publicado na portaria $\mathrm{n}^{\circ} 215$, de 25 de fevereiro de 2016 (BRASIL, 2016). O zoneamento objetiva minimizar os riscos relacionados aos fenômenos climáticos e permite a cada município identificar a melhor época de plantio das culturas, nos diferentes tipos de solo e ciclos de cultivares, podendo ser adotada por produtores rurais e agentes financeiros (IGNÁCIO et al., 2016).

A soja tem recebido grande destaque no cenário estadual. Segundo dados da Conab, a produção saiu de 9,8 mil toneladas em 2001/02 para 79,2 mil toneladas na safra 2014/15. Esse aumento também se refletiu na área colhida e na produtividade. Enquanto nos anos inicias a área colhida era 3,5 mil ha e a produtividade $2.800 \mathrm{~kg} / \mathrm{ha}$, nos anos finais, a área passou para $24 \mathrm{mil}$ ha e a produtividade, para $3.300 \mathrm{~kg} / \mathrm{ha}$. Produtores do Mato Grosso e da regiáo sul do país são atraídos pelas condiçôes climáticas da região, preço das terras e áreas planas. Enquanto no restante do país o plantio da soja ocorre entre setembro e dezembro, com colheita de janeiro a abril, em Roraima a produção se dá na entressafra (plantio em maio e colheita em setembro), dando alta competitividade pela logística facilitada para escoamento do grão e sua comercialização.

No campo da fruticultura, deve-se apoiar o desenvolvimento de cadeias produtivas de espécies nativas (tucumanzeiro, cupuaçuzeiro, açaizeiro, pupunheira, taperebá, araçá, cajueiro etc.) e exóticas (laranjeira, maracujazeiro, bananeira, abacaxizeiro etc.), visando o abastecimento de Boa Vista e, possivelmente, de Manaus. Durante os meses de junho e julho, o tucumá coletado em Roraima chega a abastecer, respectivamente, $19 \%$ e $21 \%$ do fruto consumido em Manaus (DIDONET e FERRAZ, 2014). 
O cajueiro anão precoce lançado pela Embrapa em 1987 tem a sua origem no germoplasma de cajueiro anão proveniente de Roraima introduzido no Campo Experimental de Pacajus, Ceará, em 1956. O cupuaçu é citado como fruta de alto potencial, devido ao fato de propiciar uma produtividade duas vezes superior a de outros estados. Um fator limitante é a ocorrência da mosca-das-frutas, que impede a comercialização "in natura" para outros estados e exportação (DEUS; ADAIME, 2013). Quanto à horticultura e produção de aves e ovos, deve-se visar o abastecimento de Boa Vista e municípios próximos, pois há pouca diversidade de produtos, qualidade limitada e preços elevados. Problemas de irrigação, pragas e doenças, carência de assistência técnica e extensão rural são grandes limitantes da horticultura local.

A silvicultura é pouco representativa, mas se sustenta especialmente com as culturas de acácia, eucalipto e teca. Em Roraima, cabe destacar a introdução da Acacia mangium, pela empresa Ouro Verde Agrosilvopastoril Ltda., pertencente ao agrônomo suíço Walter Vogel, em 1999, visando ao fornecimento de matéria-prima para serraria e celulose, e conta, atualmente, com uma área plantada de aproximadamente 30 mil hectares. Em que pesem as críticas sobre o empreendimento, trata-se de repor com cobertura vegetal áreas que estavam completamente desmatadas e degradadas (HOMMA, 2015). Madeiras como acácia e eucalipto são ainda destinadas à combustão, e têm cultivo às margens de rodovias na regiáo do "lavrado" (savanas). O extrativismo vegetal tem lugar com a colheita de frutos, folhas e tronco de diversas espécies (CARVALHO; CARVALHO; MORAIS, 2016).

Quanto à pecuária de corte, devem-se focar esforços na recuperação de pastagens degradadas, quantificadas em 772 mil hectares (TERRACLASS, 2014). Neste sentido, deve-se incentivar a adoção do sistema ILPF como ferramenta de recuperação e/ou renovação das pastagens degradadas. Neste sistema, o estado ainda tem a possibilidade de realizar duas safras anuais, sendo elas compostas por uma cultura principal e um segundo cultivo (safrinha), ou a opção pela engorda de bois na entressafra, aliando ainda a produção de madeira de forma integrada. Com a renovação/ reforma dos pastos, espera-se melhorar os índices de produção (U.A./ha). Projeções para os próximos 20 anos indicam que o estado pode duplicar sua produção de carne anual, por meio de pequeno aumento da área de pastagem, mas impulsionado por ganhos em rendimento no campo e na agroindústria (BARBOSA et al., 2015).

Recuperar as perdas nos últimos dez anos nos plantéis de suínos (-65\%) e aves (-58\%) é fundamental incentivar aves de postura e corte e a suinocultura com a inclusão de pequenos produtores, dando acesso a rações, matrizes, assistência técnica e abatedouros certificados e de qualidade. Para isso, deve-se usar como exemplo de sucesso a aquicultura, com aproveitamento de lagos naturais, que vem crescendo apoiada na produção de tambaqui e matrinxã, o que fez de Roraima o terceiro maior produtor de peixes redondos do Brasil, uma parte abastecendo a cidade de Manaus (HOMMA, 2017; IBGE, 2015).

Devido à quantidade de terras acessíveis a preços abaixo dos grandes centros produtores de commodities agrícolas, o preço das terras em Roraima vem numa escalada positiva desde 2010. Houve grande valorização em todas as áreas avaliadas, seja em campo nativo de fácil ou difícil acesso, mata, pastagem de alta e baixa capacidade de suporte de pastejo animal e terras agrícolas de alta e baixa produtividade. As terras da região de Boa Vista (predomínio de cerrado) custam aproximadamente o dobro que em Caracaraí (floresta). De forma geral, o preço médio de áreas agrícolas do estado gira em torno de R \$ 1.900,00/ha. Contudo, a procura por áreas virgens no Lavrado de Boa Vista e por pastos de Caracaraí levou à valorização destas regiôes, que chegam a custar $\mathrm{R} \$ 2.500,00 \mathrm{e}$ $\mathrm{R} \$ 1.800,00 /$ ha, respectivamente (AGRIANUAL, 2016). Este preço atrativo gerou a migração de produtores das regiōes Centro-Sul para o estado, que possui fatores climáticos favoráveis à agricultura, com muitas culturas apresentando desempenho superior ao de outras regióes tradicionais brasileiras. 


\section{QUADRO DE INFRAESTRUTURA}

Roraima tem recebido investimentos do Programa de Aceleração de Crescimento² (PAC) do governo federal. Entre 2011 e 2014 o estado recebeu cerca de $\mathrm{R} \$ 2,86$ bilhōes em obras. $\mathrm{O}$ valor pós 2014 gira em torno de $\mathrm{R} \$ 1,12$ bilhão, distribuído em ordem decrescente de valor nos eixos: transportes, habitação, cidades, água e luz, comunidades e energia. O montante aplicado no estado representa $0,5 \%$ dos investimentos do PAC no Brasil, e tem como obras estratégicas melhorias na Rodovia BR432, urbanizaçáo da Vila Novo Paraíso, a entrada de acesso da BR-401 e a linha de transmissão Manaus - Boa Vista (Linhão). Roraima depende $72 \%$ do seu consumo de energia proveniente da hidrelétrica de Guri, Venezuela, cujo contrato vigora até 2021, enquanto náo ocorrer a conexão com a energia proveniente da hidrelétrica de Tucuruí. Apesar de possuir os melhores índices de trafegabilidade de rodovias da Região Norte, é necessário melhorar a BR-174, que liga Boa Vista a Manaus, além dos ramais e acessos em áreas agrícolas.

A construção da BR-174, mostrada na figura 4, caminho atual para escoamento da safra, gerou a decadência do transporte fluvial e de alguns centros urbanos, como o de Caracaraí. Com isso, a navegação estadual está limitada ao rio Branco e com baixa eficiência. A navegação só é possível no trecho da foz, com cerca de $440 \mathrm{~km}$. O porto de Caracaraí encontra-se desativado, dadas as precárias condiçôes do cais. A movimentação é feita diretamente nas barrancas do rio, o que dificulta as operaçóes de embarque/desembarque. O trecho Caracaraí - Boa Vista, com extensão de aproximadamente $150 \mathrm{~km}$, tem navegabilidade prejudicada por se encontrar em zona encachoeirada nos primeiros $14 \mathrm{~km}$, num desnível de 7,5 metros, conhecida como Corredeiras do Bem Querer.

A falta de infraestrutura adequada também impacta a produção e a produtividade, pois a malha viária é insuficiente para a chegada de insumos e para escoamento da produção. Deve-se explorar melhor

\footnotetext{
${ }^{2}$ www.pac.gov.br. O governo federal estuda lançar em 2017 o Programa Avançar, que substituirá o atual PAC.
}

a posição estratégica de Roraima, que permite o escoamento da produçáo, por via rodoviária, para a Venezuela e pelo porto de Itacoatiara (AM), aproveitando frete reverso com insumos (calcário) em ambas as rotas. A introdução das culturas graníferas, especialmente soja e milho, é importante para o aproveitamento de áreas de cerrado, além de alavancar outros processos produtivos, entre eles a pecuária, a piscicultura e a criaçáo de animais médios e pequenos (verticalização). Com o aumento da escala, espera-se a reduçáo dos custos com insumos, aumentando a competitividade de diversas cadeias da agropecuária estadual. Há diversas oportunidades de investimentos para o estado de Roraima, sendo a principal delas relacionada ao transporte internacional, com acessos à Venezuela e à Guiana, que podem resultar em rotas mais curtas a mercados e portos internacionais, mostrada na figura 5. Ressalta-se, que as convulsóes políticas pós-morte de Hugo Chavez (1954-2013) colocam a Venezuela em rota de incerteza para os investidores.

Trabalhar com essa possibilidade é de suma importância para abertura de novos mercados de exportação e importação, beneficiando diversas cadeias do agronegócio de Roraima. Existe ainda a Zona de Processamento e Exportação de Roraima, localizada em Boa Vista, que busca agregação de valor dos produtos regionais e exportação de commodities agrícolas. 
Figura 4 - Via atual de escoamento da produção

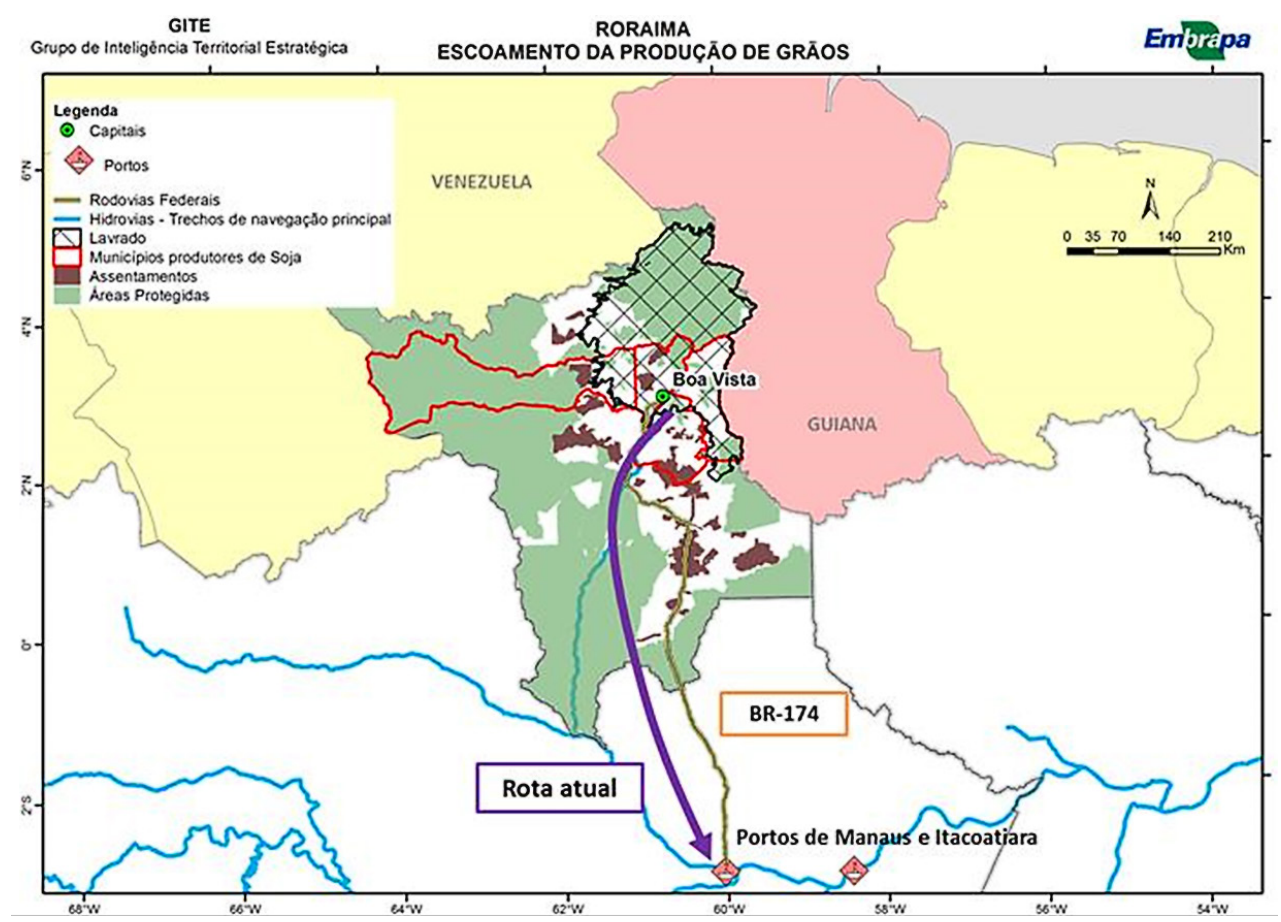

Fonte: Elaboração dos autores, 2016

Figura 5 - Via desejada de escoamento de grãos

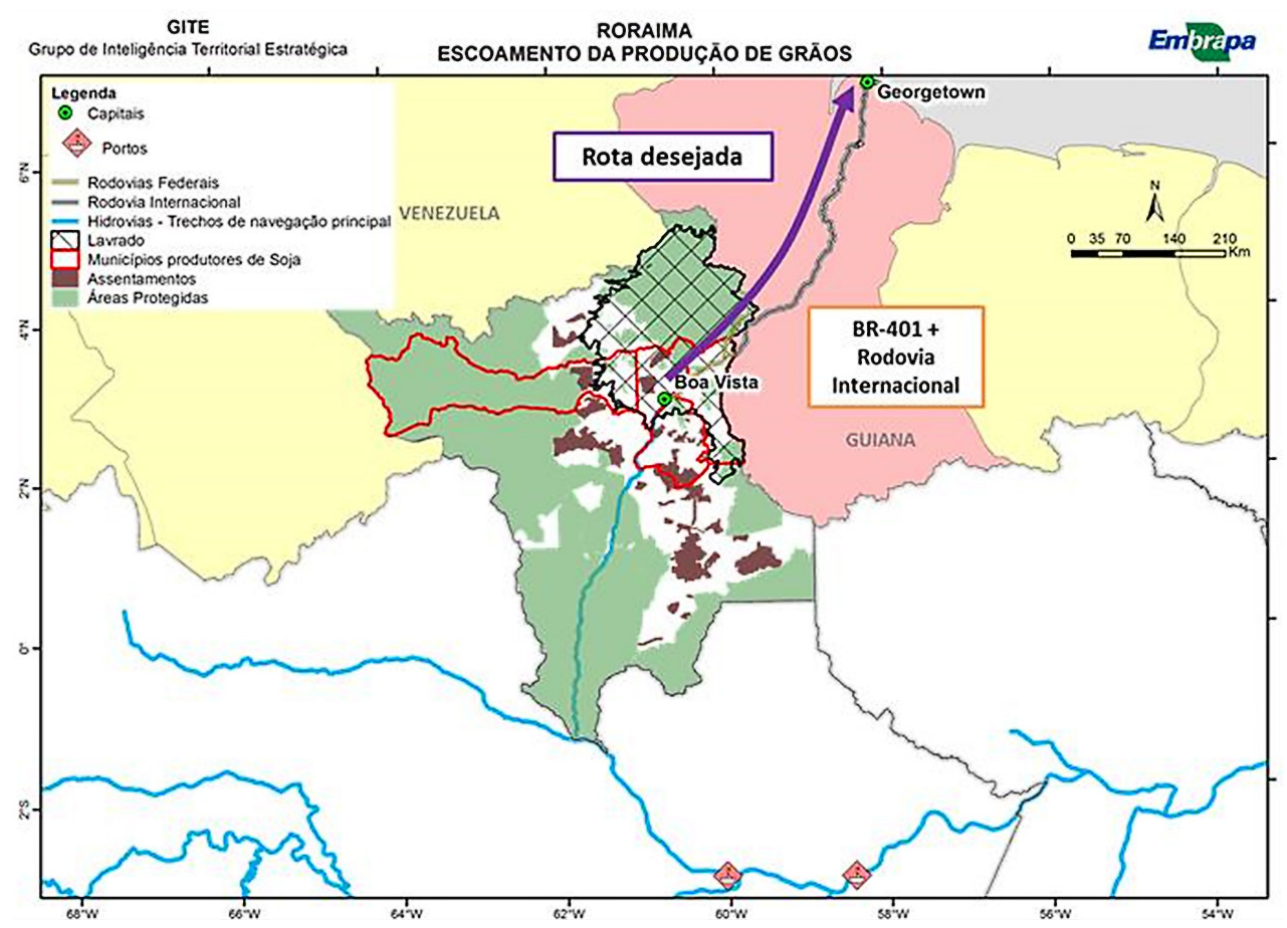

Fonte: Elaboração dos autores, 2016 


\section{QUADRO SOCIOECONÔMICO}

Os dados que embasaram a caracterizaçáo socioeconômica dos municípios de Roraima no que tange à agropecuária provêm dos levantamentos censitários dos estabelecimentos agropecuários feitos pelo IBGE em 2006. Os dados utilizados são resultado de uma agregação dos microdados em nível municipal feita por pesquisadores da Embrapa (ALVES et al., 2013). Nesse cenário, os agricultores são o objeto de estudo, náo o meio físico ou a produçáo agropecuária. Por esse motivo, o foco na análise recai sobre a renda bruta dos estabelecimentos em salários mínimos mensais (SLM).

Por definição, renda bruta é a produção vendida, autoconsumo e indústria caseira. Para transformar renda bruta em salários mínimos, utilizou-se o salário mínimo vigente em 2006 de R \$300,00, seguindo modelo proposto por Alves et al. (2013). Quatro classes de renda bruta foram utilizadas para classificar os estabelecimentos:
- $[0,2)$ : renda de até 2 salários mínimos mensais, identificados como muito pobres;

- $[2,10):$ renda entre 2 e 10 salários mínimos mensais, identificados como pobres;

- [10,200): renda entre 10 e 200 salários mínimos mensais, identificados como médias;

- Acima de 200: renda acima de 200 salários mínimos mensais, identificados como ricas.

Tendo em vista a forte vertente ideológica que associa a distribuição da terra com a distribuição de renda, a informação de área dos estabelecimentos também foi considerada segundo Alves et al. (2013). Os estabelecimentos foram particionados em dois grupos: estabelecimentos com área inferior ou igual a 100 ha e com área superior a 100 ha. Tem-se, portanto, para cada município e classe de renda: o número de estabelecimentos agropecuários em cada grupo de área e o número total de estabelecimentos.

Tabela 6 - Total de estabelecimentos rurais de Roraima classificados por renda

\begin{tabular}{ccrr}
\hline \multicolumn{2}{c}{ Total de Estabelecimentos } & \multicolumn{2}{c}{$\%$} \\
\hline Faixa de Salários Mínimos & $\mathbf{N}^{\circ}$ estabelecimentos & \multicolumn{1}{c}{ Estado } \\
\hline 0 a 2 & Muito pobres & 4.214 & $73 \%$ \\
\hline 2 a 10 & Pobres & 1.120 & $19 \%$ \\
\hline 10 a 200 & Médias & 456 & $8 \%$ \\
\hline$>200$ & Ricas & 10 & $0 \%$ \\
\hline & Total & $\mathbf{5 . 8 0 0}$ & $\mathbf{1 0 0 \%}$ \\
\hline
\end{tabular}

Fonte: Alves et al. (2013) 
Tabela 7 - Distribuição dos estabelecimentos agropecuários por área e classe de renda

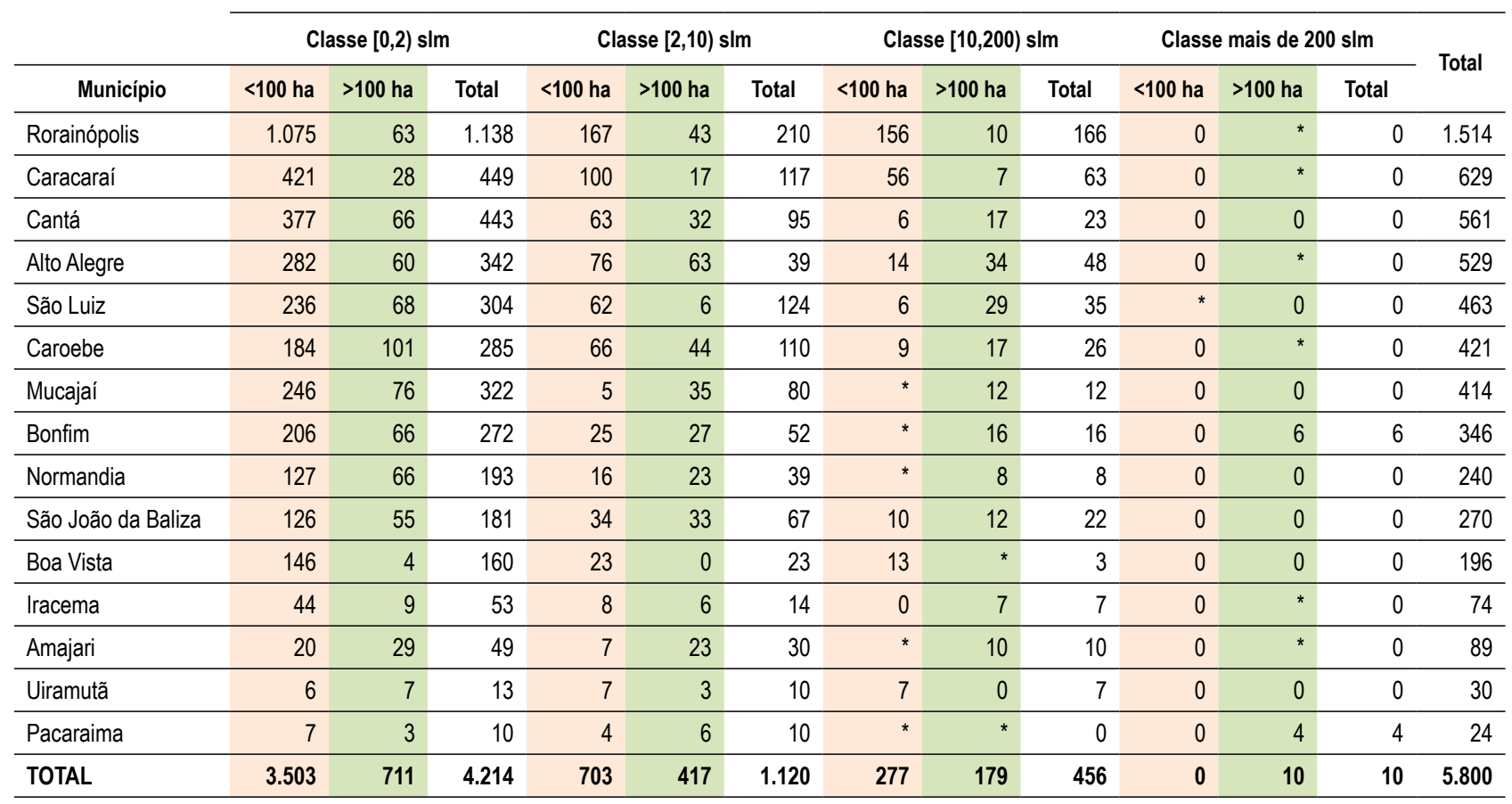

Fonte: Alves et al. (2013)

O total dos 5.800 estabelecimentos agropecuários dos municípios de Roraima está distribuído na seguinte proporção de classes: 72,7\% muito pobres (4.214), $19,3 \%$ pobres (1.120), 7,9\% média (456) e $0,2 \%$ rica (10 estabelecimentos) (tabela 6). Estratificando por área, temos que $93,8 \%$ dos estabelecimentos com área inferior ou igual a 100 ha estáo nas classes pobre e muito pobre, sendo que $78,1 \%$ deles estão na classe muito pobre. Ainda considerando a área inferior ou igual a 100 ha, nenhum estabelecimento agropecuário está na classe rica. Por outro lado, dos estabelecimentos com área superior a 100 ha, somente $14,4 \%$ deles estão nas classes média e rica, e destes, $0,8 \%$ são ricos (tabela 7). Cada classe de renda, mostrada nas colunas, foi estratificada em subcolunas de acordo com a área. Os municípios foram ordenados decrescentemente pela quantidade de estabelecimentos.
Como pode ser visto nessa tabela, apenas 4 dos 15 municípios concentram mais de $50 \%$ dos estabelecimentos agropecuários de Roraima (Rorainópolis, Caracaraí, Cantá e Alto Alegre totalizam 3.233 estabelecimentos). Essa concentração também se reflete na renda bruta. Considerando as classes muito pobre e pobre, os 4 municípios somados representam $56 \%$ e $50 \%$, respectivamente. A figura 6 ilustra a repartição e a concentração espacial do número de estabelecimentos agropecuários nos municípios, estratificados por classe de renda. 
Alfredo Kingo Oyama Homma / Evaristo Eduardo de Miranda

Figura 6 - Número de estabelecimentos agropecuários nos municípios estratificados por classe de renda: a) muito pobre, b) pobre, c) média e d) rica

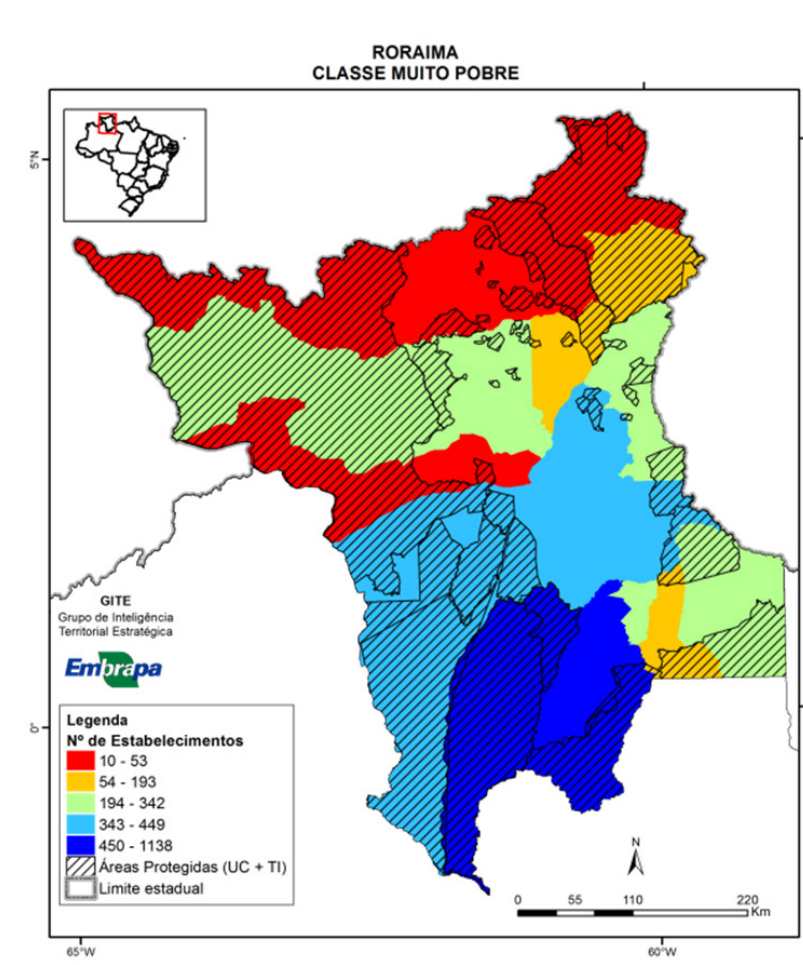

(a)

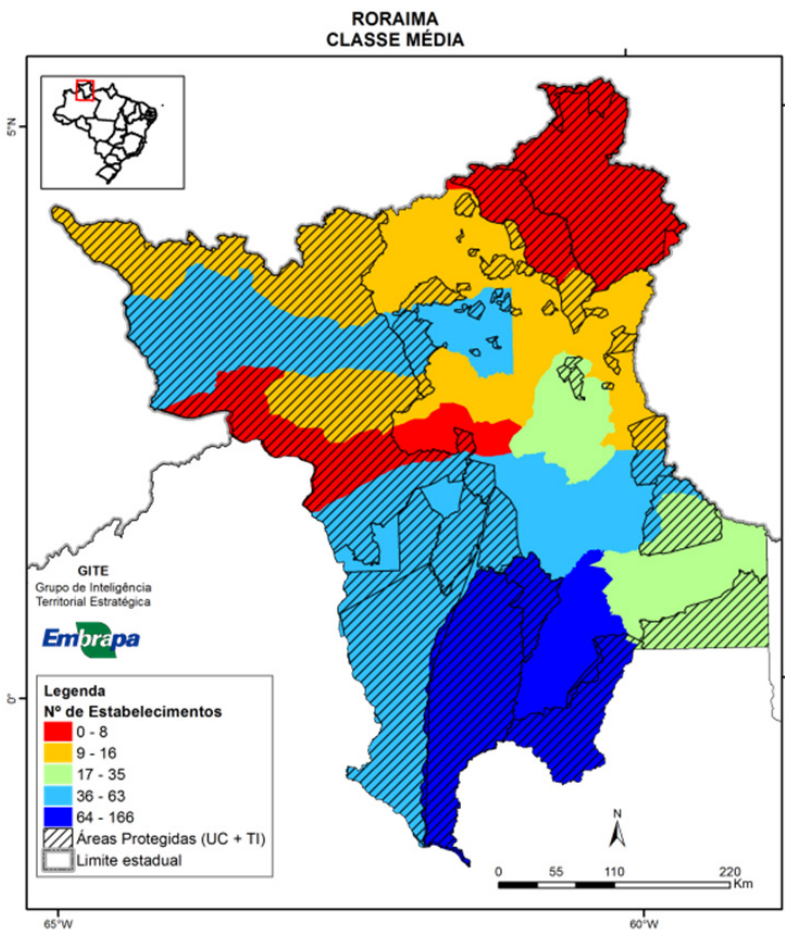

(c)

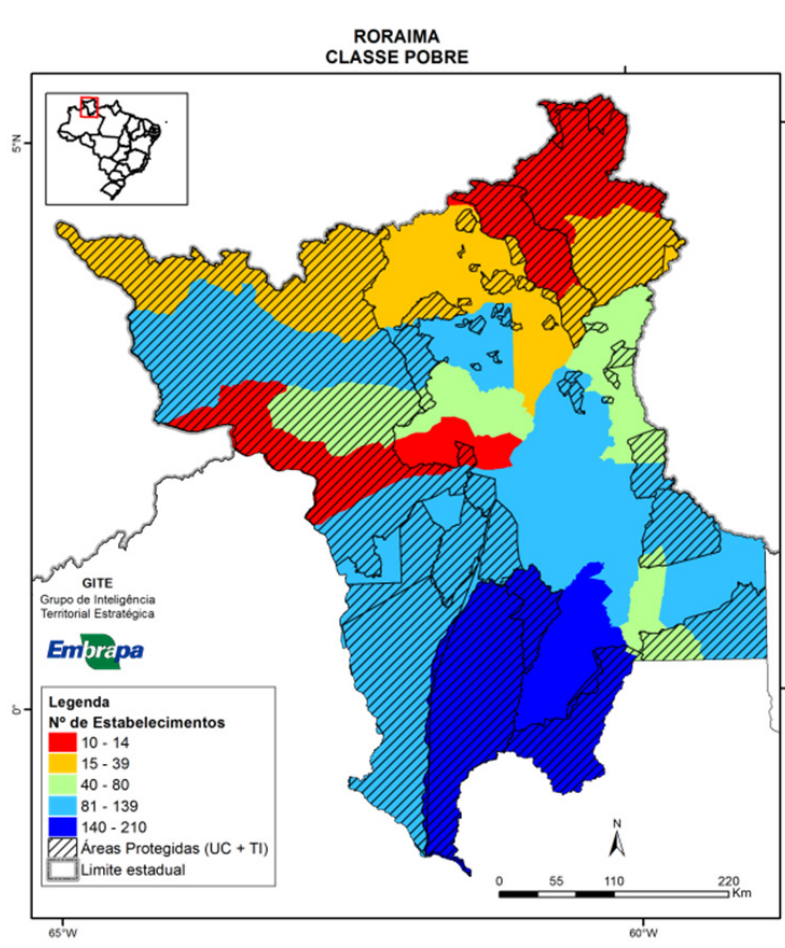

(b)

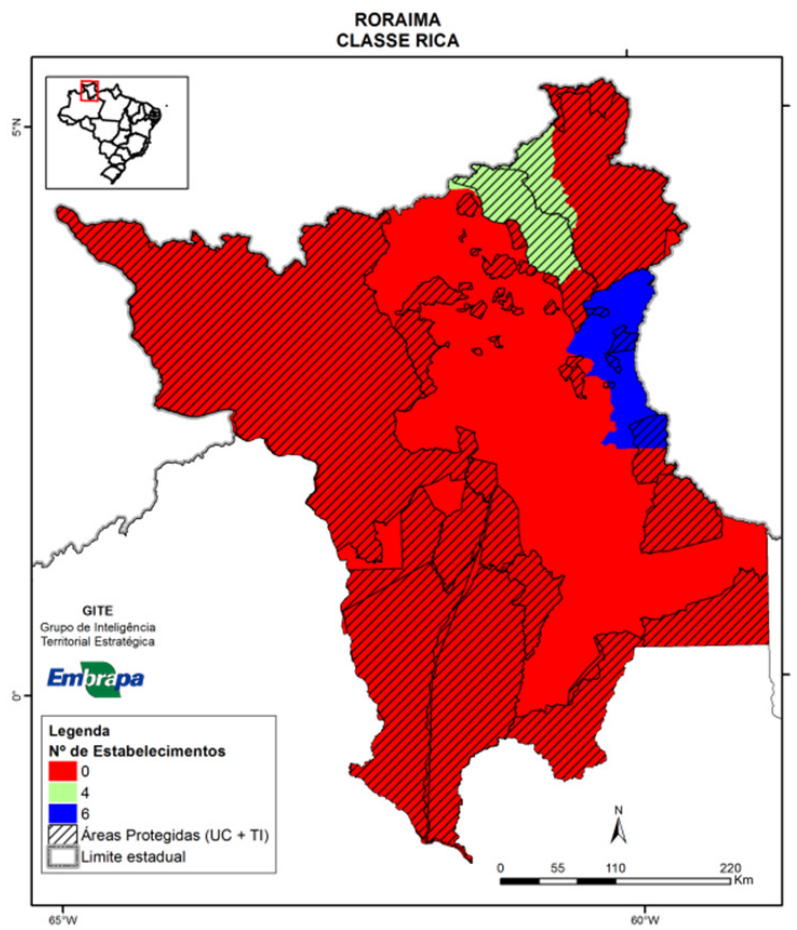

(d)

Fonte: Alves et al. (2013) 


\section{CONSIDERAÇÕES FINAIS}

Uma discussão exclusiva do contexto fundiário ou agrário resultaria em interpretaçóes superficiais acerca dos desafios a serem enfrentados pelo estado. Com $73 \%$ do seu território legalmente atribuído para unidades de conservação, terras indígenas e assentamentos rurais, a produção agrícola do estado enfrenta numerosos desafios para se fortalecer do ponto de vista econômico, social e ambiental. Em 2006, dos quase seis mil estabelecimentos agropecuários, $82 \%$ situavam-se na zona da pobreza, ou seja, recebiam até no máximo 10 salários mínimos mensais de renda bruta. Soma-se a esse cenário a ausência de reservas internas de insumos para a agricultura e a grande distância dos centros de distribuiçáo, encarecendo, com a logística, a aquisição de matéria-prima para uso nas lavouras.

A modelagem do SITE permite a inclusão de novos planos de informação a depender das perguntas a serem respondidas. As novas demandas devem surgir após cada validação junto aos diversos públicos-alvo locais, garantindo a retroalimentaçáo do sistema com base em novas demandas. As primeiras oportunidades ocorreram durante a III Reuniáo de Tecnologias para a Cultura da Soja no Cerrado, em Boa Vista, e durante a Oficina Territorial do Projeto Fundo Amazônia, em Rorainópolis. Nestes, estiveram presentes membros do setor produtivo, da agricultura familiar, dos órgãos de extensão rural, de órgáos governamentais, estaduais e federais, ligados ao agronegócio, onde foram realizadas duas seções de brainstorm.

A importância da transferência dessas informaçōes ao público-alvo é fundamental para a validação e aplicabilidade do SITE Roraima. Até o momento, as análises do SITE Roraima permitiram a identificação de propostas, programas e ações necessárias ou pertinentes para o desenvolvimento sustentável da agropecuária do estado. As propostas contemplam todos os cinco quadros avaliados, bem como a interaçáo entre eles, todas passíveis de execução por meio de projetos, pesquisas e açóes de transferência de tecnologias, que busquem atuações pontuais e estratégicas para aumento da competitividade em nível municipal, regional e estadual. As propostas são listadas a seguir:

- promover a integração produtiva, sustentabilidade e competitividade da agropecuária estadual;

- garantir a segurança alimentar de Boa Vista e dos principais núcleos urbanos do estado de Roraima e reduzir o preço dos alimentos arroz, feijão e mandioca, com adoção de tecnologias e fortalecer a produção, influenciadas por conflitos fundiários, ambientais e indígenas;

- fortalecer a agricultura nativa e exótica para mercado local e excedente para exportaçáo sobretudo para Manaus;

- apoiar a produçáo de abacate, banana, caju, goiaba, citros, mamão, melancia e meláo;

- incentivar o manejo e plantio de tucumanzeiro para abastecimento de Manaus;

- agroindústrias com escala: banana, coco, cupuaçu, maracujá, açaí, pupunha, castanha;

- potencializar cultivos comerciais (soja e milho) e uso de máo-de-obra (cacaueiro, dendezeiro, pimenteira-do-reino, guaranazeiro e cafeeiro) para pequenos produtores;

- desenvolver a horticultura nas áreas periurbanas para atender o mercado local;

- fortalecer a piscicultura com espécies amazônicas e híbridas, buscando a sua integração (peixes da amazônia);

- apoiar o selo amazônico do peixe, certificaçáo de origem geográfica;

- fortalecer a pecuária de corte visando o abastecimento regional (livre de aftosa);

- reflorestamentos com nativas e exóticas (acacia mangium, eucalipto); 
- recuperação de pastagens (ILPF, Programa ABC, Programa Balde Cheio);

- recuperação da fertilidade dos solos visando o aproveitamento de 772 mil ha degradados com potencial uso para pastagem, grãos ou outras atividades;

- facilitar a disponibilidade de insumos modernos a preços competitivos e a prática da rochagem;

- verticalização de cadeias com escala (grãos para suínos, aves, laticínios etc.);

- infraestrutura local (micrologística, eletrificação rural, ampliar armazenagem, defesa agropecuária);

- estados de fronteira são fundamentais no controle da mosca da fruta;

- ampliar a governança fundiária pela titulaçáo imediata dos produtores rurais;

- concessão de direito real de uso (CDRU) ou título definitivo da terra;

- priorizar titulação em assentamentos com mais de 10 anos de criação;

- dar atençáo para 34 assentamentos e 13 mil famílias em 1,1 milhão ha;

- macrologística e micrologística com a melhoria dos ramais existentes;

- concessóes, PPPS, PAC 3, PMI, Projeto Crescer;

- melhorias na BR-174 (Manaus - Boa Vista);

- apoiar parcerias externas, com investimentos públicos e privados, visando o desenvolvimento da agricultura estadual;

- inserção social das comunidades indígenas;

- programa de acesso à água potável e saneamento básico;

- formalização para emissão de notas fiscais de produtos extrativistas;
- pesquisa e inovação: foco nos problemas identificados;

- possibilidade de unir gastronomia ao turismo: criar roteiros e rotas;

- necessidade de parceria diferenciada com sebrae para alavancar o agronegócio;

- desburocratizar a fundação estadual do meio ambiente e recursos hídricos;

- ampliar a classe média rural;

- identificar municípios, público-alvo e cadeias produtivas prioritárias;

- apoiar iniciativas com ou sem sistemas agroflorestais (SAFs) para reflorestamentos mistos;

- produção de pequenos animais em integração articulada com a produção de milho.

\section{AGRADECIMENTOS}

Agradecimentos aos pesquisadores da Embrapa Eliseu Alves e Geraldo da Silva e Souza (Embrapa Sede) por ceder os dados sumarizados do Censo Agropecuário 2006, ao pesquisador Fernando Luís Garagorry Cassales pelo auxílio na metodologia de análise da produção.

\section{REFERÊNCIAS}

AGRIANUAL 2016: anuário da agricultura brasileira. Informa Economics FNP, 2016. Disponível em: <http://agrianual.com.br/> Acesso em: 14 mai. 2016.

ALVES, E.; SOUZA, G. S.; GOMES, E. G. Contribuição da Embrapa para o Desenvolvimento da Agricultura no Brasil. 1 ed. Brasília, DF: Embrapa Informação Tecnológica, 2013. 291p.

BARBOSA, F. A. et al. Cenários para a pecuária de Corte amazônica. Centro de Sensoriamento Remoto e Escola de veterinária da Universidade Federal de Minas Gerais. Aliança da Terra. Virginia Tech Woods Hole Research Center, 2015. 
BRASIL. Código Florestal Brasileiro. Lei no 12.651, de 25 de maio de 2012. Disponível em: < http://www.planalto.gov.br/ccivil_03/_ ato2011-2014/2012/lei/112651.htm> Acesso em: 18 maio. 2016.

BRASIL. Decreto no 8.586, de 9 de dezembro de 2015. Disponível em: <http:/www.planalto.gov.br/ccivil_03/_Ato2015-2018/2015/ Decreto/D8586.htm> Acesso em: 16 jun. 2016.

BRASIL. Portaria no 215, de 25 de fevereiro de 2016. Disponível em: <http://www.agricultura.gov.br/assuntos/riscos-seguro/ risco-agropecuario/portarias/safra-2016-2017/roraima/arquivos/ SOJARR.pdf> Acesso em: 16 jun. 2016.

CARVALHO, T.M.; CARVALHO, C.M.; MORAIS, R.P. Fisiografia da paisagem e aspectos biogeomorfológicos do lavrado, Roraima, Brasil. Revista Brasileira de Geomorfologia, v.17, p.94 107, 2016.

CASTRO, G.S.A.; CRUSCIOL, C.A.C.; DA COSTA, C.H.M.; FERRARI NETO, J.; MANCUSO, M.A.C. Surface application of limestone and calcium-magnesium silicate in a tropical no-tillage system. Journal of soil science and plant nutrition, v.16, n.2, p.362379, 2016. Disponível em: < https://dx.doi.org/10.4067/S071895162016005000034> Acesso em: 20 mar. 2017.

CONAB. Companhia Nacional de Abastecimento. Série histórica da produção de soja. Disponível em: < http://www.conab.gov.br/ conteudos.php?a=1252\&> Acesso em: 06 out. 2015.

DEUS, E. G.; ADAIME, R. Dez anos de pesquisas sobre moscasdas-frutas (Diptera: Tephritidae) no estado do Amapá: avanços obtidos e desafios futuros. Biota Amazônia, v. 3, n. 3, p. 157-168, 2013.

DIDONET, A. A.; FERRAZ, I. D. K.O comércio de frutos de tucumã (Astrocaryum aculeatum G. Mey - Arecaceae) nas feiras de Manaus (Amazonas, Brasil). Rev. Bras. Frutic. [online], v.36, n.2, p.353-362, 2014.

DEPARTAMENTO NACIONAL DE INFRAESTRUTURA DE TRANSPORTES- DNIT. Disponível em: <http://www.dnit.gov. br/planejamento-e-pesquisa/dnit-geo/> Acesso em: 17 abr. 2016.

DEPARTAMENTO NACIONAL DE PRODUÇÃO MINERAL - DNPM.. Sistema de Informações Geográficas da Mineração SIGMINE. Disponível em: <http://sigmine.dnpm.gov.br/ webmap/> Acesso em: 14 mai. 2015.

ENVIRONMENTAL SYSTEMS RESEARCH INSTITUTE- ESRI. ArcGIS Desktop: release 10.3. Redlands, California, USA, 2013.

FUNAI. Fundação Nacional do Índio. Terras indígenas do Brasil. Disponível em: <http://www.funai.gov.br> Acesso em 20 mar. 2014.

GARAGORRY, F. L.; CHAIB FILHO, H. Elementos de agrodinâmica. Brasília, DF: Embrapa SGE, 2008. Disponível em: <http://www22.sede. embrapa.br/web/sge01/estatisticaagricola/dinamica/relatorioagrodinamica. pdf> Acesso em: 29 out. 2014.

.; GREGO, C. R.; MIRANDA, E. E. de; OSHIRO, O. T.; QUARTAROLI, C. F.; KOBAYASHI, A. G. Concentração e dinâmica de queimadas de 2000 a 2006. Campinas, SP: Embrapa Monitoramento por Satélite, 2011. (Boletim de Pesquisa e Desenvolvimento, 16).

GARAGORRY, F. L.; PENTEADO FILHO, R. de C.; MIRANDA, E. E. de; MARRA, R. Concentração de conjuntos de produtos agrícolas com base no seu valor. Brasília, DF: Embrapa SGI, s/d. Disponível em: < http://www22.sede.embrapa.br/ web/sge01/ estatisticaagricola/concentra/prodbr > Acesso em: 28 jul. 2016.

HOMMA, A.K.O. A Terceira Natureza da Amazônia. Revista Paranaense de Desenvolvimento, Curitiba, v.38, n.132, p.27-42, jan./ jun. 2017.

Biopiratas, inventores e desbravadores que mudaram a agricultura na Amazônia. Olhares Amazônicos, v.4, n.1, p.730-746, jan./jun. 2015.

INSTITUTO BRASILEIRO DE GEOGRAFIA E ESTATÍSTICA IBGE. Disponível em: <www.ibge.gov.br> Acesso em: 04 jul. 2016.

\section{INSTITUTO CHICO MENDES DE CONSERVAÇÃO DA} BIODIVERSIDADE- ICMBio . Geoprocessamento: mapas temáticos $e$ dados geoestatísticos de unidades de conservação federais. Disponível em: <http://www.icmbio.gov.br> Acesso em: 04 jul. 2016.

IGNÁCIO, R.; SILVA, E.V. da; CARVALHO, T.M. de; SILVA, C.L.R. da. Planejamento e ordenamento territorial do Estado de Roraima: utopia ou realidade?. Revista Internacional de Direito Ambiental e Politicas Públicas, n. 8, p. 137-152, 2016.

INSTITUTO NACIONAL DE COLONIZAÇÃO E REFORMA AGRÁRIA - INCRA. Assentamentos rurais do Brasil. Disponível em: <http://acervofundiario.incra.gov.br> Acesso em: 20 mar. 2014.

MARTINHO, P.R.R. et al. Avaliação da aptidão agrícola das áreas disponiveis do Estado de Roraima. Campinas, SP: Embrapa Monitoramento por Satélite, 2016.

MIRANDA, E. de E.; MAGALHĀES, L. A.; CARVALHO, C. A. de. Proposta de Delimitação Territorial do MATOPIBA. Campinas, SP: Embrapa Monitoramento por Satélite, 2013. 18p. Disponível em: <www.embrapa.br/gite/publicacoes/NT1_ DelimitacaoMatopiba.pdf> Acesso em: 15 jul. 2016.

MINISTÉRIO DO MEIO AMBIENTE - MMA. Download de Dados Geográficos. Disponível em: <http://mapas.mma.gov.br/ i3geo/ datadownload> Acesso em: 27 mar. 2014.

MINISTÉRIO DO MEIO AMBIENTE - MMA. Mapas de Cobertura Vegetal dos Biomas Brasileiros. 2006. Disponível em: <http://mapas.mma.gov.br/mapas/aplic/probio/datadownload. htm> Acesso em: 14 mar. 2014.

PARAHYBA, R. E. Calcário Agrícola. 2009.

Disponível em: <http://www.simineral.org.br/arquivos/ EconomiaMineraldoBrasil2009CalcrioDNPM.pdf> Acesso em: 30 set. 2016. 


\section{SECRETARIA DE POLÍTICAS DE PROMOÇÃO DA}

IGUALDADE RACIAL - SEPPIR. Sistema de Monitoramento:

Programa Brasil Quilombola. Disponível em: <http://www.

seppir.gov.br>.

TERRACLASS. Disponível em: <http://www.inpe.br/cra/projetos_ pesquisas/terraclass2014.php> Acesso em: 17 jul. 2016.

WANDER, A. E. et al. Concentração espacial e dinâmica da produção de arroz no Brasil, de 1975 a 2005. Santo Antônio de Goiás, GO: Embrapa Arroz e Feijão, 2013. (Documentos / ISSN 1678-9644; 283). Disponível em: <http://ainfo.cnptia.embrapa.br/ digital/bitstream/item/80031/1/seriedocumentos-283.pdf> Acesso em: 5 jul. 2016. 